Check for updates

Cite this: RSC Adv., 2018, 8, 15533

Received 23rd February 2018

Accepted 12th April 2018

DOI: 10.1039/c8ra01625a

rsc.li/rsc-advances

\section{Influence of surface modifications of a nanostructured implant on osseointegration capacity - preliminary in vivo study}

\author{
Maciej Janeczek, ${ }^{a}$ Patrycja Szymczyk, ${ }^{\text {D }}$ Maciej Dobrzynski, ${ }^{c}$ Olga Parulska, ${ }^{d}$

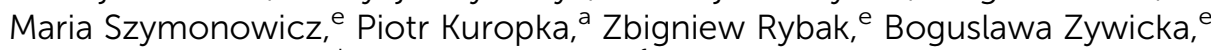 \\ Grzegorz Ziolkowski, ${ }^{b}$ Krzysztof Marycz, ${ }^{f}$ Aleksander Chroszcz, ${ }^{a}$ Aleksandra Skalec, ${ }^{a}$ \\ Sara Targonskag and Rafal J. Wiglusz iD *gh
}

In response to the need for implant materials characterized by high biocompatibility a new type of nanostructured Ti6Al7Nb implants for osseous tissue regeneration have been fabricated. The nanostructured cylindrical implants were manufactured in accordance with 3D CAD data using the Selective Laser Melting (SLM) method. Implants were subjected to chemical polishing using a mixture of nitric acid and fluoride (test group) as well as cleaned in distilled water and isopropyl alcohol (control group). The structural and morphological properties of the obtained samples were determined by using XRD (X-ray powder diffraction), TEM (transmission electron microscopy) and SEM (scanning electron microscopy) techniques. The particle size was verified and calculated by Rietveld method to be in the range of 25-90 nm. In the present study, experimental in vivo tests concerning implants fabricated from a nanostructured Ti6Al7Nb alloy, which may substitute bone tissue, were discussed in detail. The control group and test group were used in the study. The animal model was New Zealand rabbit. The implants were implanted into skull fornix and observed after 1,2 and 3 months. The results of macroscopic and microscopic analysis proved better osseointegration of chemically modified implants.

\section{Introduction}

Tissue engineering is an interdisciplinary science which may be applied in the treatment of large bone defects by designing and manufacturing cellular structures., ${ }^{\mathbf{1} 2}$ Modern design and manufacturing methods based on the processing of metallic

\footnotetext{
${ }^{a}$ Department of Biostructure and Animal Physiology, Faculty of Veterinary Medicine, Wroclaw University of Environmental and Life Sciences, Kozuchowska 1, 51-631 Wroclaw, Poland

${ }^{b}$ Center for Advanced Manufacturing Technologies (CAMT-FPC), Faculty of Mechanical Engineering, Wroclaw University of Science and Technology, Lukasiewicza 5, 50-371 Wroclaw, Poland

${ }^{c}$ Department of Conservative Dentistry and Pedodontics, Faculty of Dentistry, Wroclaw Medical University, Krakowska 26, 50-425 Wroclaw, Poland

${ }^{d}$ Department of Oral Surgery, Faculty of Dentistry, Wroclaw Medical University, Krakowska 26, 50-425 Wroclaw, Poland

${ }^{e}$ Department of Experimental Surgery and Biomaterials Research, Faculty of Dentistry, Medical University, Bujwida 44, 50-368 Wroclaw, Poland

${ }^{f}$ Department of Experimental Biology, Faculty of Biology and Animal Science, Wroclaw University of Environmental and Life Sciences, ul. Norwida 27B, 50-375 Wroclaw, Poland

${ }^{g}$ Institute of Low Temperature and Structure Research, Polish Academy of Sciences, Okolna 2, 50-422 Wroclaw, Poland

${ }^{h}$ Centre for Advanced Materials and Smart Structures, Polish Academy of Sciences, Okolna 2, 50-950 Wroclaw, Poland. E-mail: R.Wiglusz@int.pan.wroc.pl; Fax: +4871-344-10-29; Tel: +48-71-395-41-59
}

powders, such as Selective Laser Melting (SLM), have enabled the development of individualized implants with a customized geometry and complex internal architecture. ${ }^{3}$ Orthopedic patients with implanted biomaterials are most vulnerable to perioperative infections, which can be devastating to the replaced limb, complicating additional surgical procedures or increasing risk of patient mortality. ${ }^{4}$ Contemporary as well as veterinary regenerative medicine commonly uses modern tissue engineering techniques to replace damaged osteoarticular structures. Bone scaffolds or implants are a specific example of biomaterials at risk of infection. In case of significant bone loss the organism is unable to regenerate by its own means. Therefore, the loss needs to be replaced with an appropriate implant.

The leading etiologic infectious agents of surgical scaffolds are Gram-negative bacteria Pseudomonas aeruginosa and Grampositive bacteria Staphylococcus aureus, opportunistic pathogens causing both acute and chronic nosocomial infections. Patients with a weakened immune system or undergoing invasive surgical procedures are particularly prone to infections caused by these pathogens. These bacteria are responsible for about $33 \%$ of infections in orthopedic surgery with various kinds of implants. ${ }^{5-7}$ The metallic biomaterials include titanium alloys, which are still the dominant material used in implantology, due to its beneficial properties. Application of titanium alloys in the most challenging fields of technology and 
Table 1 Technological parameters for SLM²2

\begin{tabular}{llll}
\hline $\begin{array}{l}\text { Laser } \\
\text { power }(\mathrm{W})\end{array}$ & $\begin{array}{l}\text { Spot } \\
\text { size }(\mu \mathrm{m})\end{array}$ & $\begin{array}{l}\text { Scan velocity } \\
\left(\mathrm{mm} \mathrm{s}^{-1}\right)\end{array}$ & $\begin{array}{l}\text { Layer } \\
\text { thickness }(\mu \mathrm{m})\end{array}$ \\
\hline $25 \mathrm{~W}$ & 100 & 200 & 50
\end{tabular}

implantation effectiveness largely depends on compliance with the requirements of mechanical or functional characteristics but also depends on the surface quality of the implant. For medical applications, the most commonly used is pure titanium CP (ASTM F67) and Ti6Al4V ELI alloy (ASTM F136). New alloys with reduced content or completely free of such elements as vanadium and aluminium are constantly being developed. According to literature review, they are known as allergenic potential and can lead to neurogenic disorders. The Ti6Al7Nb alloy is a new generation material that is gaining popularity due to weak solubility of niobium oxide in tissue environment, and non-toxicity of oxide layers or soluble ions. Additionally, unlike the so far used alloys, does not contain vanadium, thanks to that it can find application in medical applications. Thanks to the modified chemical composition, this alloy is characterized by a more beneficial set of mechanical properties higher corrosion resistance, additionally niobium that substitutes vanadium in this alloy improve its biocompatibility. ${ }^{8,9}$

Surface modification consisting in the formation of the porous coating on the orthopedic devices can increase the corrosion resistance, to ensure an appropriate level of compatibility with the surrounding tissues, and can also accelerate the new regenerated bone and tissue healing. In general the porous coatings are produced by sintering mesh or fibers, by plasma spraying of titanium and ceramics particulates or using sol-gel method. Under appropriate conditions, the growth of bone into the implanted part results in long-term mechanical fixation to the host skeleton, thanks that working life of implanted device in a human body can reach several years. ${ }^{10,11}$ The success of implant fixation by osseointegration has been well established for many reconstructive procedures. ${ }^{12,13}$

The application of porous structures allows increasing flexibility and global porosity of bone implants while decreasing their weight and density. The porous structure of an implant, links the implant and the osteoblasts are obtained, as well as extensive transport of body fluids within the implant-tissue connection. $^{\mathbf{1 4 , 1 5}}$
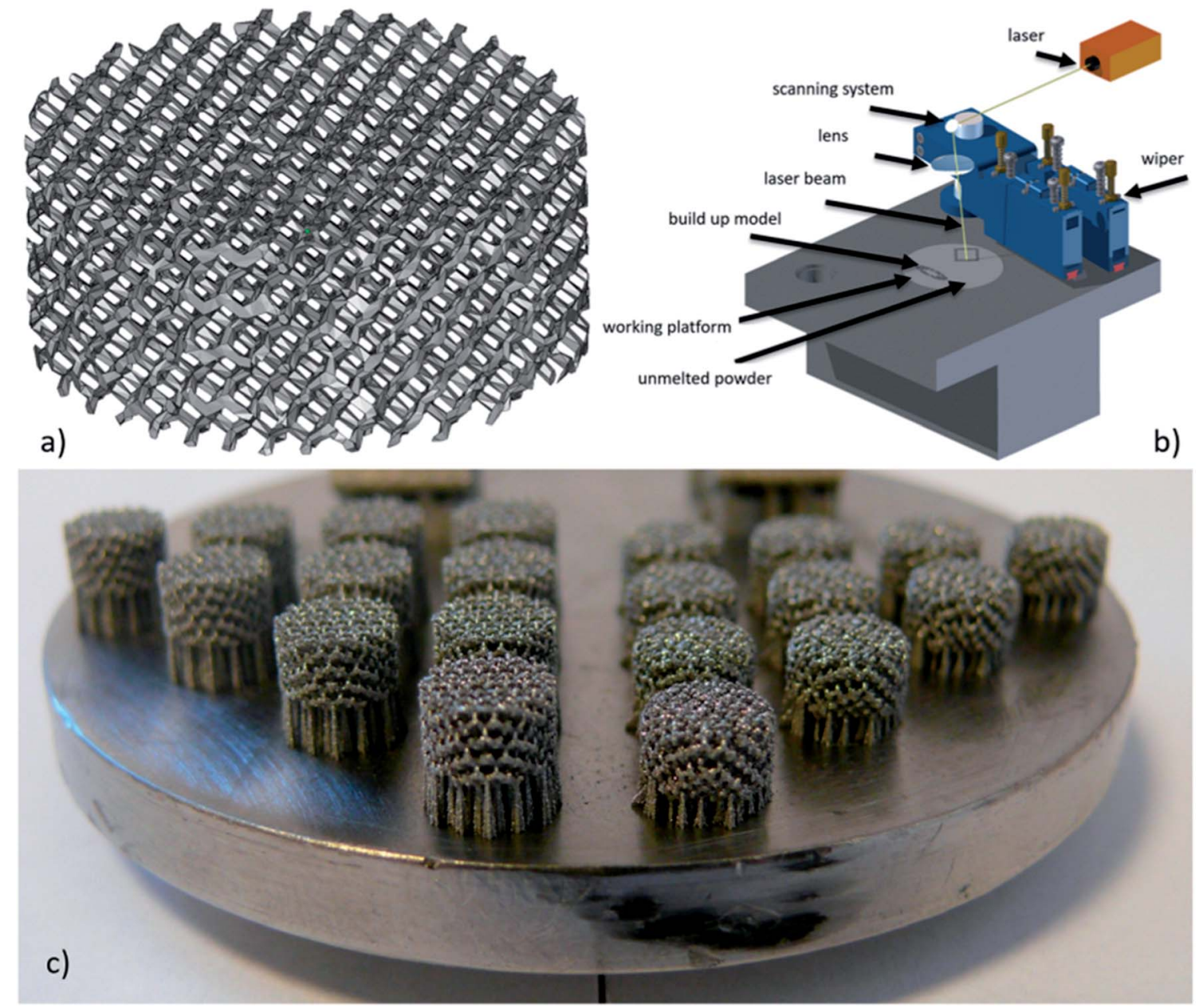

Fig. 1 (a) 3D CAD data model; (b) SLM device schema; (c) implants produced by selective laser melting. 

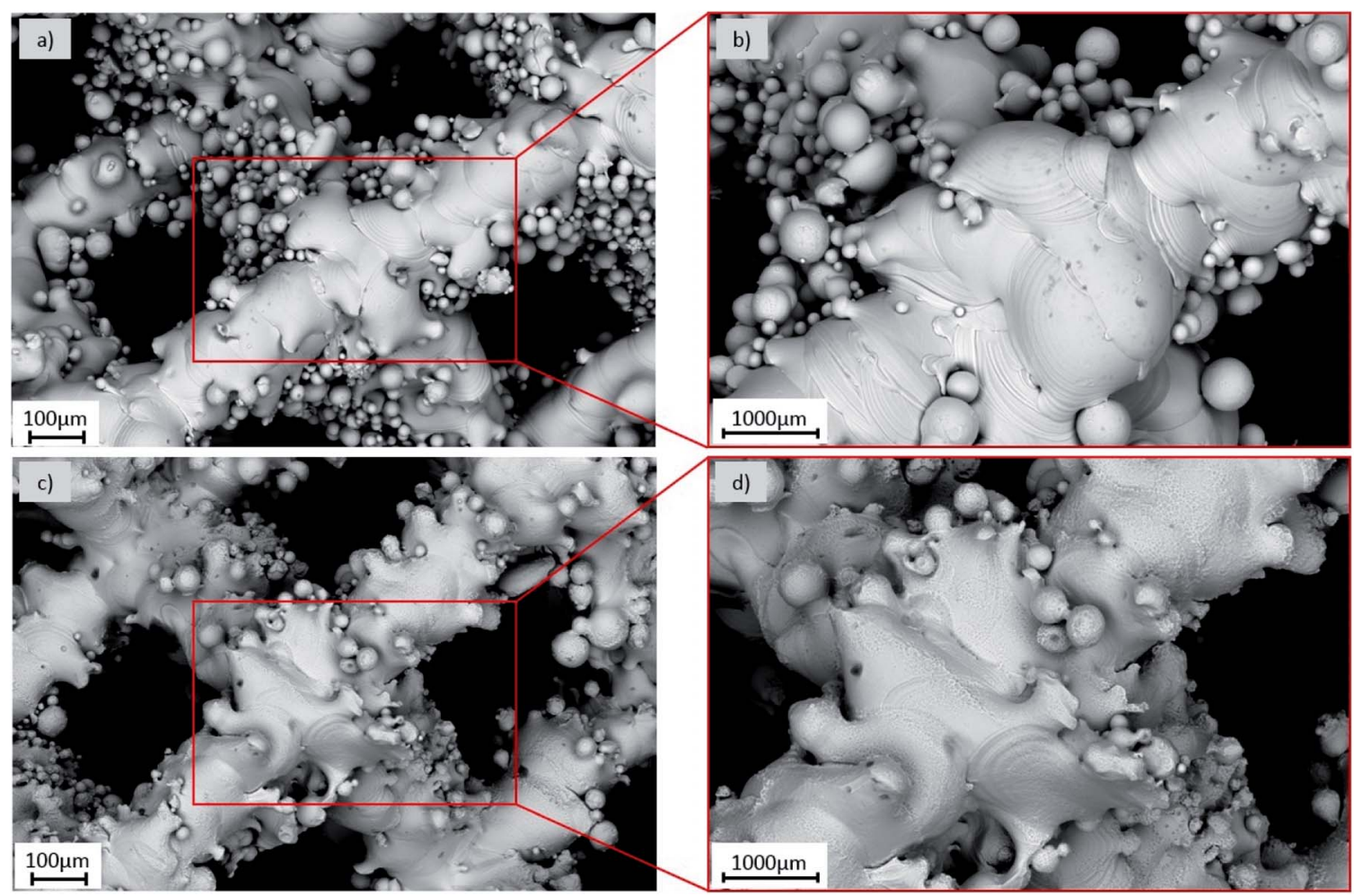

Fig. 2 Implants surfaces: ( $a$ and $b$ ) after the SLM process (A); ( $c$ and d) after chemical etching (B).

The individually matched bone implant with complex geometric shape and an irregular structure can be manufactured they require special treatment. A standard methods of surface coating with use of HAp (hydroxyapatite) is a challenge for a small pore size, because channels clogging may contribute to the formation of inflammation within such implant structures. Over the past decade, interest in chemical modifications of implant surfaces has widely grown in order to improve the implant-bone interface. ${ }^{16}$ Moreover, the

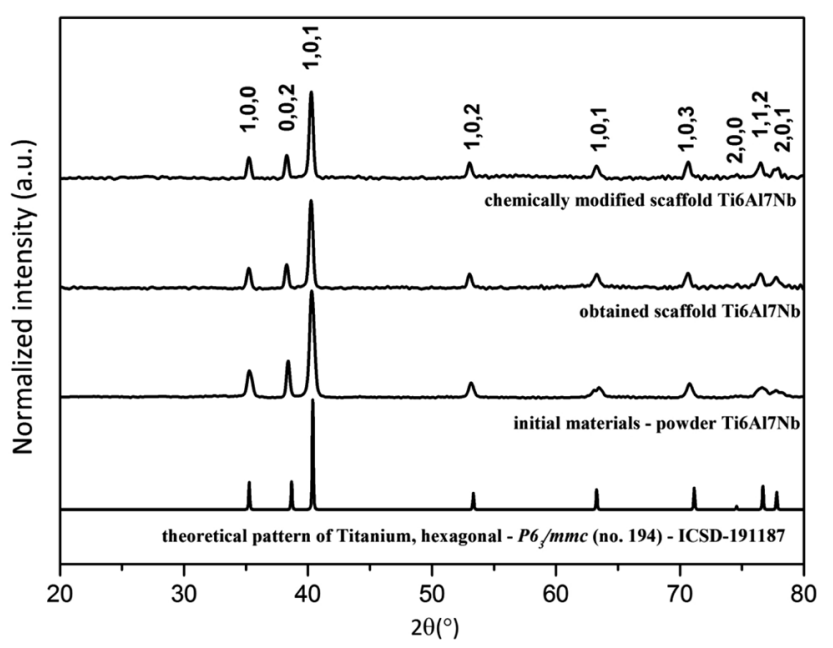

Fig. 3 X-ray powder diffraction patterns of the Ti6Al7Nb powder and the Ti6Al7Nb implants. titanium implants could be covered with a desired layer thickness to improve their biocompatibility and biointegration within the bone tissue. ${ }^{17-19}$ The structure of the outer layer could be porous and used for carrying antiinflammatory substances to minimize the risk of aftersurgery complications or to speed up the healing process. The possibility of bio-imaging of the outer layer might be useful in the evaluation of layer/implant ageing, and to follow the integration of the implant with bone tissue by

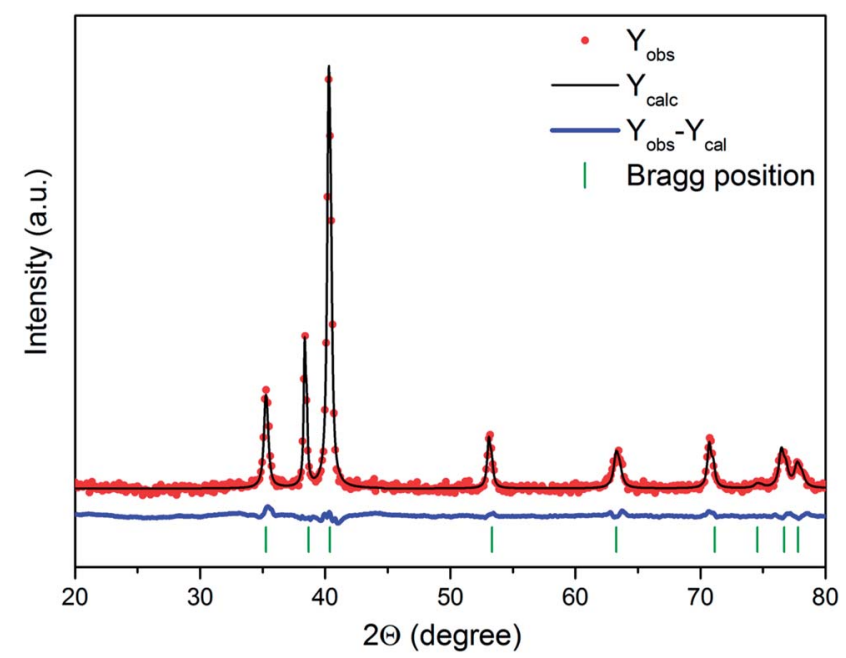

Fig. 4 Representative result of the Rietveld analysis for the Ti6Al7Nb nanopowder (red - fitted diffraction; blue - differential pattern, column - reference phase peak position). 


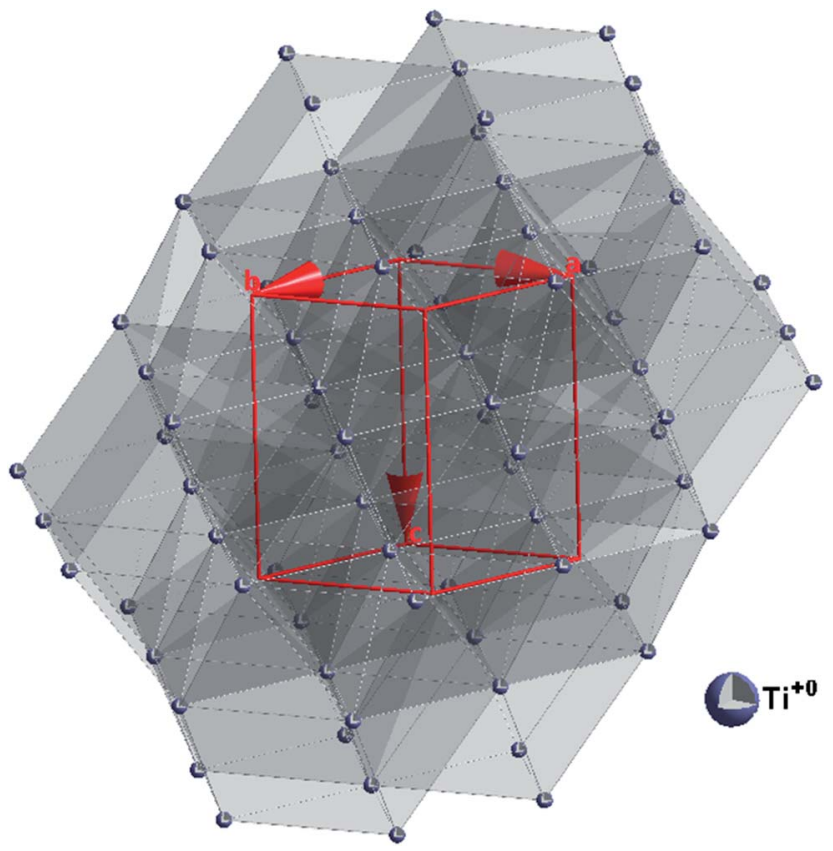

Fig. 5 Projection of the titanium unit cell.

Table 2 Unit cell parameters $(a, c)$, cell volume $(V)$, grain size as well as refine factor $\left(R_{\mathrm{w}}\right)$ for the different form of $\mathrm{Ti}^{0}$ calculated by Maud 2.68 software

\begin{tabular}{llllll}
\hline Sample & $a(\AA)$ & $c(\AA)$ & $V\left(\AA^{3}\right)$ & Size $(\mathrm{nm})$ & $R_{\mathrm{w}}(\%)$ \\
\hline Single crystal $^{20}$ & 2.9366 & 4.6519 & 34.74 & - & - \\
$\mathrm{Ti}^{0} \quad$ Powder & 2.9365 & 4.6857 & 34.99 & 26.66 & 3.5 \\
$\quad$ Ti implant & 2.9359 & 4.6936 & 35.04 & 89.61 & 5.7 \\
Modified & 2.9351 & 4.6922 & 35.01 & 48.06 & 5.5 \\
\hline
\end{tabular}

observation of the ion diffusion upon possible re-build of the boundary tissue. ${ }^{20}$

Chemical etching based on bath dedicated to titanium alloys we can significantly reduce ability of Staphylococcus aureus and Pseudomonas aeruginosa to form biofilm on the implants surface. The presence of nitrogen and fluorine can cause this phenomenon, due to its bactericidal ability.,21

The following experiment evaluated osseointegration of Ti6Al7Nb implants produced by Selective Laser Melting (SLM) and subjected to various surface modifications implanted into the cranial bone of [mature] New Zealand rabbits.

\section{Materials and methods}

\subsection{Implant fabrication and modification}

The specimens were fabricated using SLM ReaLizer 50 device. In accordance with the ability of generating complex structures with the Selective Laser Melting method, a model of a porous unit cell in the form of cylinder, with the pore size of $600 \mu \mathrm{m}$ and $150 \mu \mathrm{m}$ strut diameter were prepared. Then, the appropriate parameters were selected and suitable conditions for the SLM process, such as a protective atmosphere was provided. Technological parameters ${ }^{22}$ used during the manufacturing process are shown in Table 1.

Samples were made of commercial Ti6Al7Nb powder (TLS Technik GmbH \& Co Spezialpulver KG) consisted of spherical particles. Chemical composition (in wt\%) of the Ti6Al7Nb powder, based on the manufacturer's certificate is as follows: $5.82 \% \mathrm{Al}, 6.58 \% \mathrm{Nb}, 0.050 \% \mathrm{Fe}, 0.165 \% \mathrm{O}, 0.006 \% \mathrm{~N}, 0.001 \% \mathrm{H}$ and $\mathrm{Ti}$ as the remainder. The contents of the determined substitution elements were in agreement with the ISO 5832-11 Standard.

Two types of implant, were tested to evaluate the effectiveness of surface modification on ability to integrate with surrounding tissue. First group of the Ti6Al7Nb samples were submitted to preliminary cleaning using ultrasonic cleaner containing $99.7 \%$ isopropyl alcohol (control group (A)). Second group of samples was also pre-cleaned in $99.7 \%$ isopropyl alcohol and then subjected to a chemical etching in ultrasonic bath with the mixture of $5 \mathrm{ml} \mathrm{HF} \mathrm{(50 \% )} \mathrm{and} 15 \mathrm{ml} \mathrm{HNO}$ (50\%) in $200 \mathrm{ml}$ of ultrapure water (test group (B)). Chemical etching time was 25 second. Reducing the time of chemical treatment with reference to previous authors' research was related to the a)

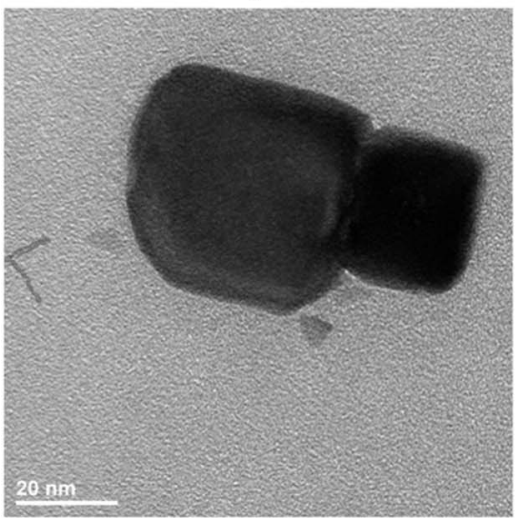

b)

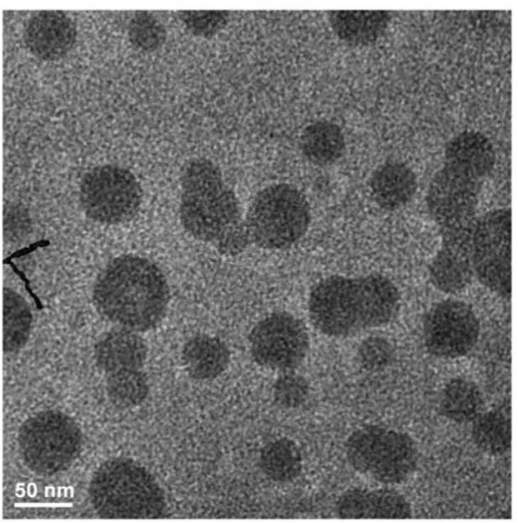

c)

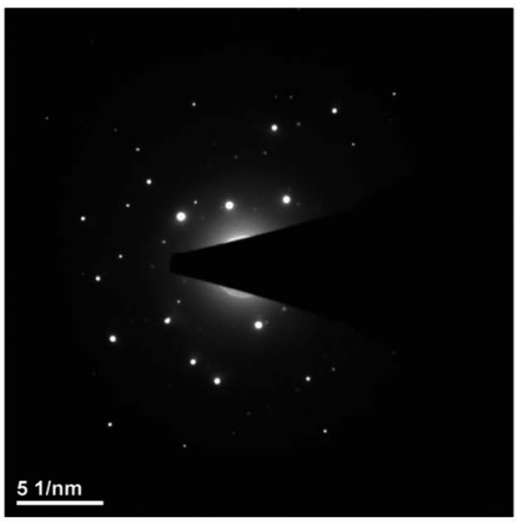

Fig. 6 Representative TEM ( $a$ and b) and SAED (c) images of the Ti6Al7Nb nanoparticles. 
A

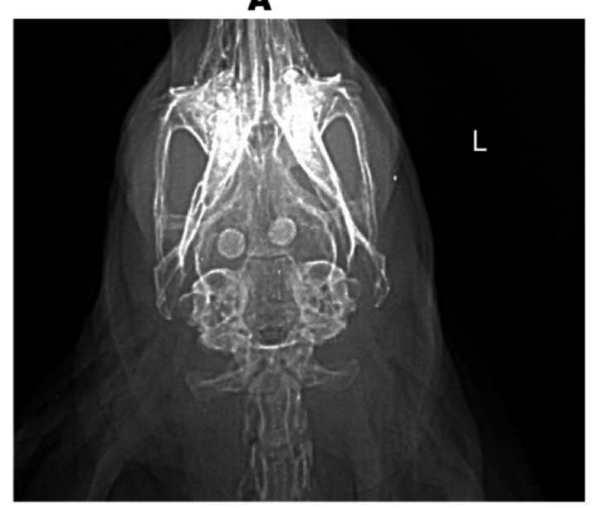

B

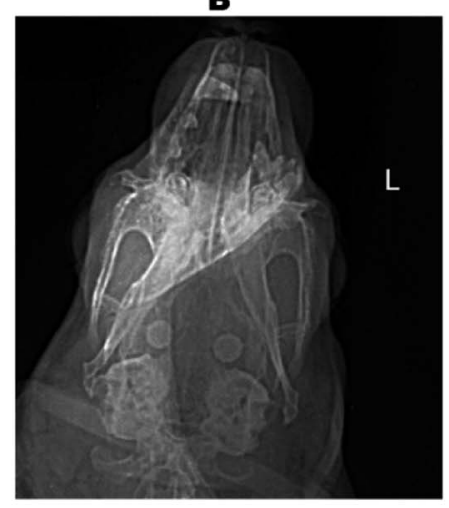

C

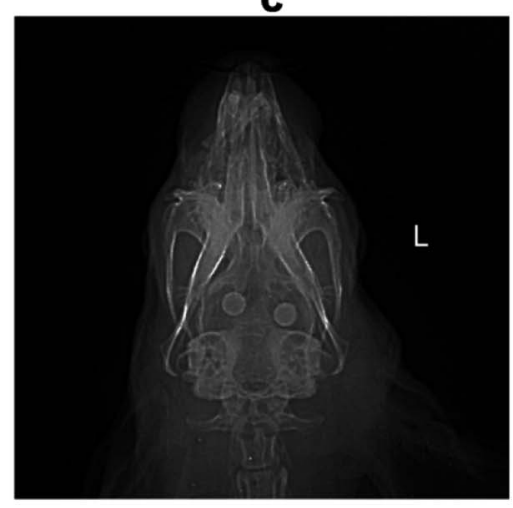

Fig. 7 Radiographic image of implanted material (A) after 1 month; (B) after 2 month; (C) after 3 month.

smaller size of the samples. Afterwards, the samples were rinsed in water (to neutralize acid) and dried in sterile airflow. Analysis of control and chemically modified samples was performed using scanning electron microscope EVO MA25 (Zeiss) and technical computed tomography (XCT).

\subsection{Materials characterization}

The structure and morphology of raw Ti6Al7Nb nanopowder and fabricated implant samples were studied using X-ray diffraction (XRD) technique, scanning electron microscopy (SEM) and transmission electron microscopy (TEM).

The X-ray powder diffraction (XPRD) patterns were measured in the $3-120^{\circ} 2 \theta$ range by using an X'Pert Pro PANalytical X-ray diffractometer equipped with Ni-filtered $\mathrm{Cu} \mathrm{K} \alpha_{1}$ radiation $\left(\mathrm{K} \alpha_{1}\right.$ $=1.54060 \AA, V=40 \mathrm{kV}, I=30 \mathrm{~mA})$. The experimental XRD patterns were compared with the standard from Inorganic Crystal Structure Database (ICSD) and analyzed.

The microstructure and morphology of the obtained implants were investigated by the scanning electron microscope

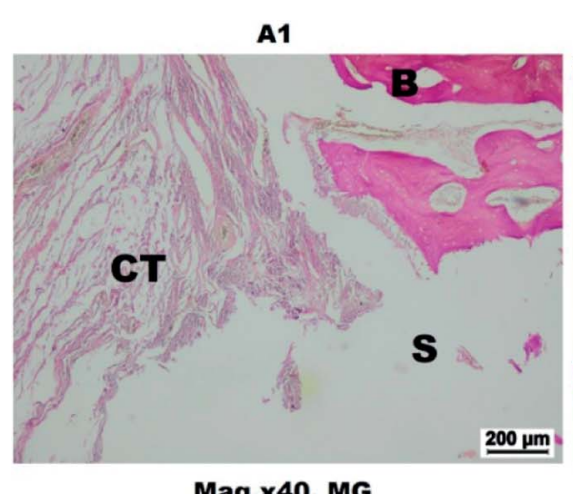

Mag.x40, MG

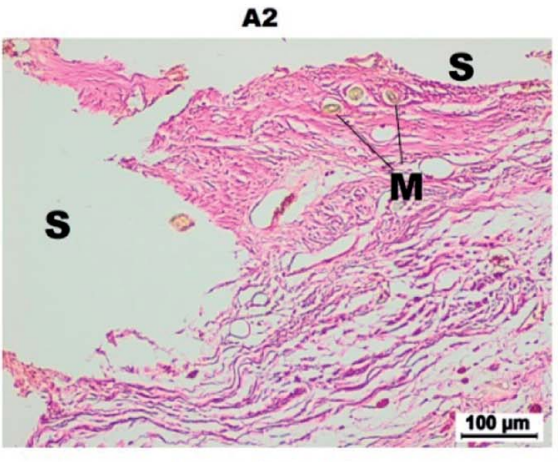

Mag.x100, vG B1

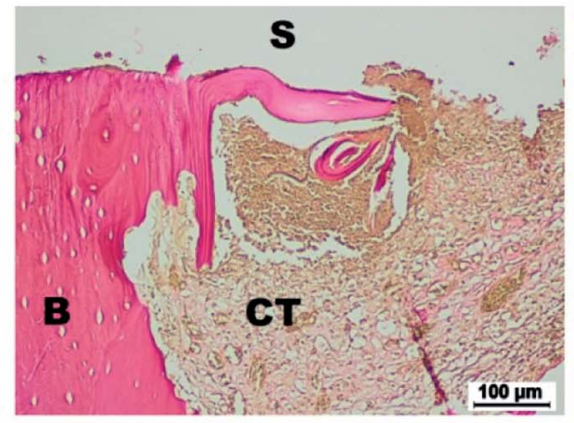

Mag.x100, MG

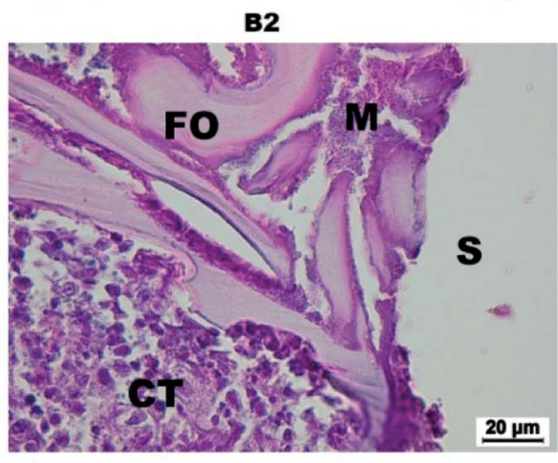

Mag.x400, MG

Fig. 8 Histological picture of implant and surrounding tissues after 1 month; A - control group; B - test group. S - implant, CT - connective tissue, B - bone, BM - bone marrow, M - material, FO - focal ossification. (A1 and A2) The space after the implant removed limited by connective tissue. (A3) The material residues are visible. (B1) The implant surrounded by connective tissue and bone. (B2) In the immediate vicinity of the implant the numerous leukocytes are visible. 

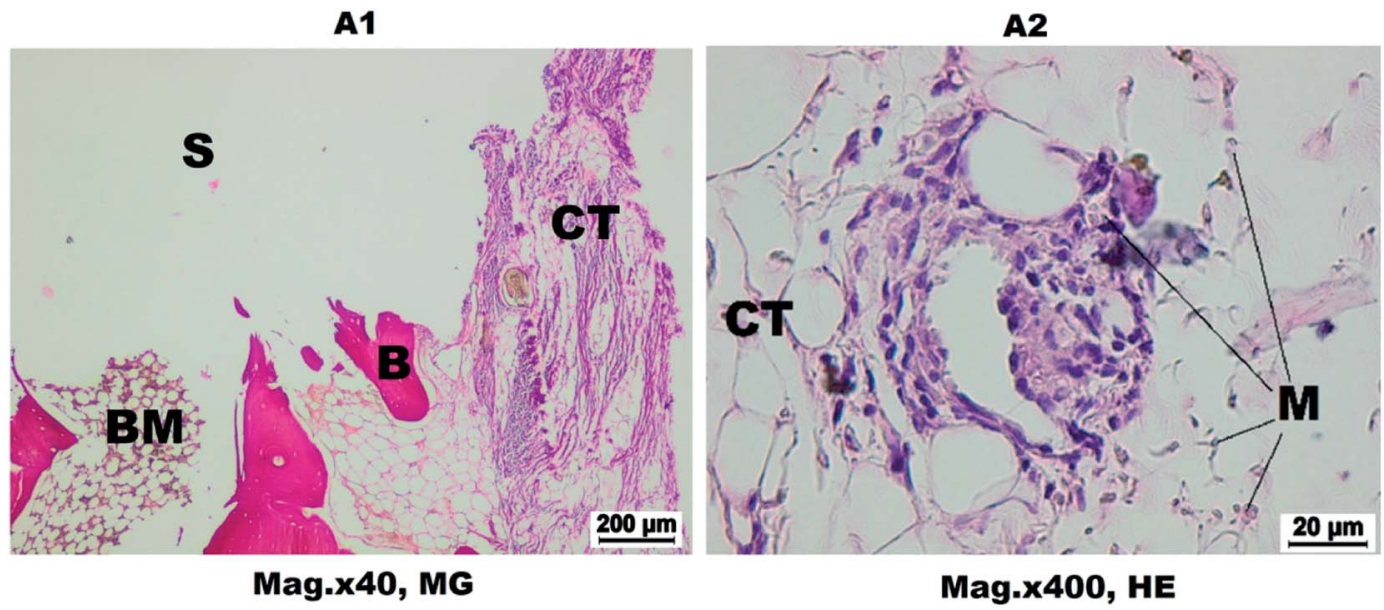

$\mathbf{B 1}$
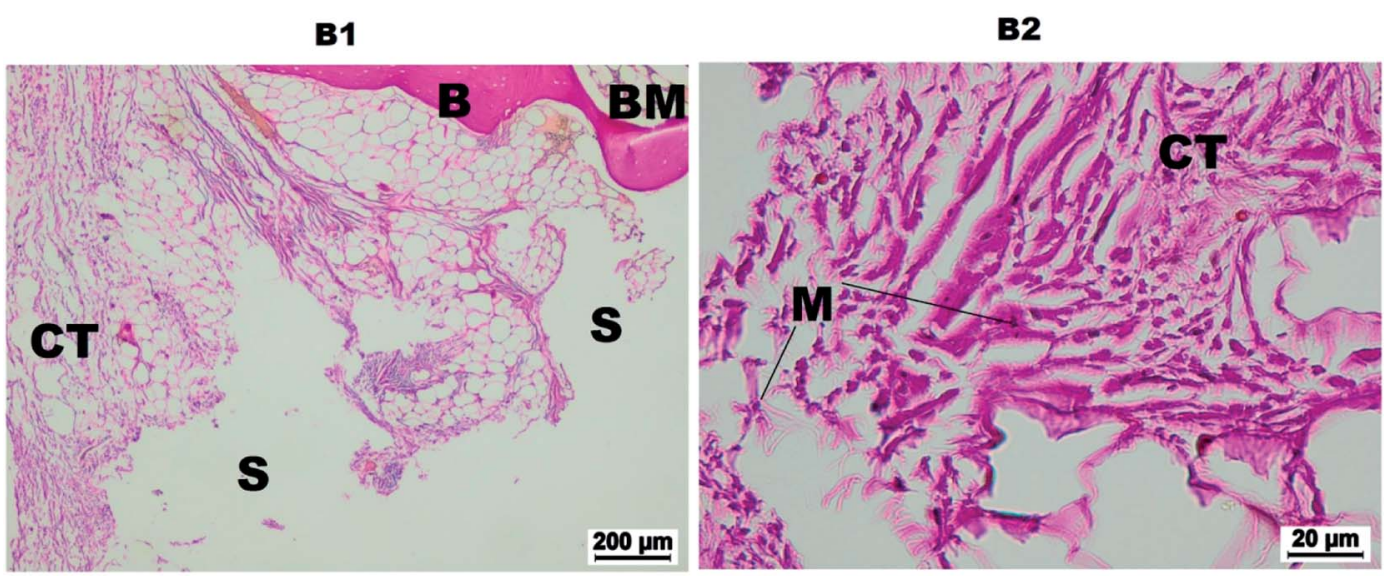

Mag.x40, MG

Mag.x400, MG

Fig. 9 Histological picture of implant and surrounding tissues after 2 months; A - control group; B - test group. S - implant, CT - connective tissue, B - bone, BM - bone marrow, M - material. (A1) The space after the implant limited by connective and bone tissue is visible. (A2) The material residues are visible in the connective tissue. (B1) Spongy bone and fibrous connective tissue surrounding the implant. (B2) In the fibrous connective tissue, the material remains are visible.

FEI Nova NanoSEM 230. Moreover, the nanoparticles were investigated by high resolution transmission electron microscopy (HRTEM) using a Philips CM-20 Super Twin microscope, operated at $200 \mathrm{kV}$. Samples for measurements were prepared by preparation of dispersion of powders in methanol. Afterwards a droplet of suspension was deposited on a copper microscope grid covered with perforated carbon. The primary size of particles was evaluated using volume weighted formula:

$$
d_{\mathrm{av}}=\frac{\sum n_{i} d_{i}{ }^{4}}{\sum n_{i} d_{i}{ }^{3}},
$$

where $d_{\mathrm{av}}$ is the average particle size, $n$ number of particles and $d$ represents particle diameter.

The Rietveld refinements of X-ray powder patterns were performed for each sample with the program Maud 2.68 software. ${ }^{23}$ The used procedure (both data-collection and refinement strategy) corresponded to the general guidelines for structure refinement using the Rietveld method (whole-profile) formulated by the International Union of Crystallography Commission on Powder Diffraction. ${ }^{24}$ The initial structural parameters of titanium were taken from: ${ }^{25}$ space group $P 6_{3} /$ $m m c, Z=2, a=2.9366 \AA$ and $c=4.6519 \AA, 1$ independent atomic position: Ti position in sites $2 d(x=0.3333, y=0.6667, z$ $=0.7500)$ and $2 d(x=0.6667, y=0.3333, z=0.2500)$.

\subsection{Evaluation of cell morphology and toxicity}

The research was carried out on primary fibroblast cell culture derived from a gingival fragment in accordance with the procedure described in the literature. ${ }^{26}$ DMEM (Sigma-Aldrich Sp. z.o.o, Poland) with the addition of $4500 \mathrm{mg} \mathrm{l}^{-1}$ glucose, $3.7 \mathrm{mg} \mathrm{l}^{-1}$ sodium bicarbonate, $1 \%$ L-glutamine with streptomycin and penicillin (Sigma-Aldrich Sp. z.o.o, Poland) and 10\% FBS (Fetal Bovine Serum, Sigma-Aldrich Sp. z.o.o, Poland) were used as the culture medium. The cells were cultured in a standard condition $\left(5 \% \mathrm{CO}_{2},(37 \pm 1){ }^{\circ} \mathrm{C}\right)$ in a Steri Cycle 381 (Thermo Scientific, Marietta, OH, USA) incubator.

The cells were trypsinized $(0.25 \%$ trypsin-EDTA, SigmaAldrich, Poland), seeded in a 6-well plate, in an amount of 1.5 $\times 105$ cells per well. After 24 hours of incubation, a test disk was placed on each well in contact with the monolayer of cells. After 

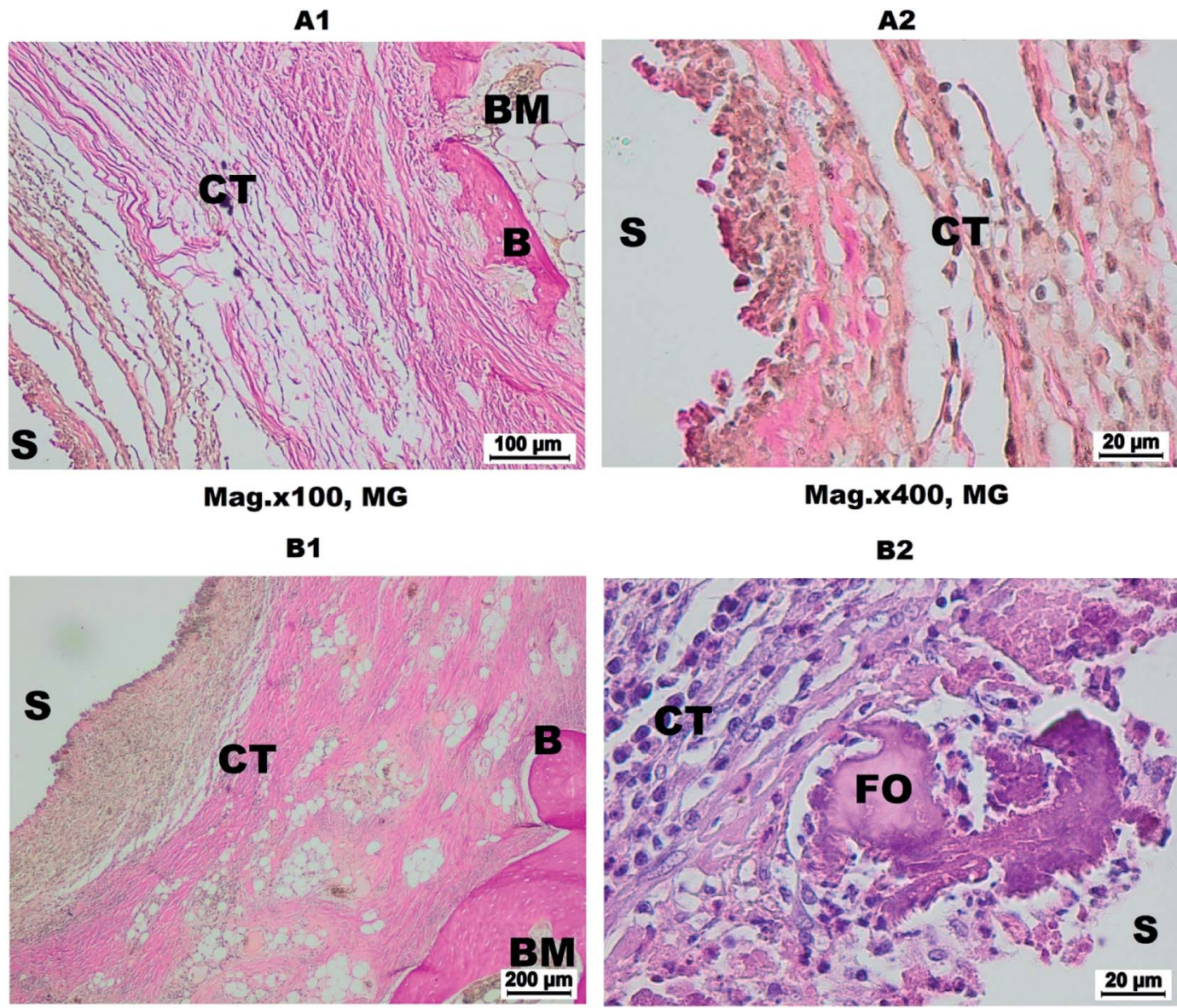

Mag.x 40, MG

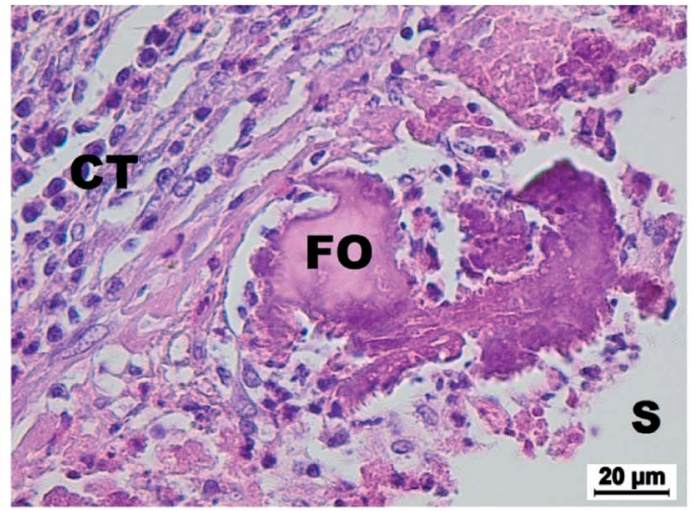

Mag.x400, HE

Fig. 10 Histological picture of implant and surrounding tissues after 3 months; (A1 and A2) control group, (B1 and B2) test group. S - implant, CT - connective tissue, B - bone, BM - bone marrow, FO - focal ossification. (A1) A double layer of band of connective tissue is visible. (A2) The rich cellular connective tissue in the immediate vicinity of the implant. (B1) The wide band of connective tissue is visible. (B2) The loose connective tissue with numerous eosinophils and bone trabeculae in the immediate vicinity of the implant covered by osteoblasts.

$48 \mathrm{~h}$ of incubation, the effect of the test material on cell morphology was assessed.

The analysis of cell morphology, adhesion and growth pattern was performed on the $3^{\text {rd }}$ month after surgery. The cells were stained using mixture of diamidino-2-phenylindole (DAPI) (Sigma Aldrich) and rhodamine phalloidin mixture (RP) (Sigma Aldrich) for cytoskeleton analysis. The samples were stained with rhodamine-phalloidin $\left(5 \mathrm{U} \mathrm{ml}^{-1}\right)$ at $4{ }^{\circ} \mathrm{C}$ overnight. After that, the cell nuclei were further stained with DAPI for $5 \mathrm{~min}$. Then the material was analysed in the fluorescence microscope Nikon 80i Eclipse with UV-2A filter (EX-330-380, DM-400, BA$420)$ and colour CCD (DS - SMc, Nikon) camera was used.

\subsection{Animals}

All animal experiments were performed in accordance with the Polish legislation and were approved by the Second Local Ethics Committee of Wroclaw University of environmental and Life Sciences (decision no. 107/2014). The study was conducted on 9 New Zealand rabbits (Oryctolagus cuniculus). The premedication included medetomidine $(0.2 \mathrm{ml}$ per animal $)$ and ketamine $(0.5 \mathrm{ml}$ per animal) i.m. Anesthesia was induced with propofol $\left(8 \mathrm{mg} \mathrm{kg}^{-1}\right)$ as an intravenous bolus; each subject was continuously monitored during the procedure and given propofol as needed. During surgery the $0.9 \%$ natrium chloride solution i.v was administered. For breadth optimisation the laryngeal mask was used. Buprenorphine i.m. $\left(0.02 \mathrm{mg} \mathrm{kg}^{-1}\right.$ BW) and enrofloxacin s.c. (5 mg kg $\left.{ }^{-1} \mathrm{BW}\right)$ was given postoperation. Each animal recovered in oxygen buster ICU cage about 1 hour.

After skin incision, soft tissues were dissected to expose the parietal bone. Then periosteum was delicately incised. A round cavity measuring $7 \mathrm{~mm}$ in diameter was drilled into the parietal bone until the dura mater was exposed. The implant was stabilized in the prepared area and the deeper tissues were sutured with material Vicryl 4-0, while skin was sutured using Amifil 3-0. Each subject received a control implant implanted in the right side of the skull and a test implant on the left.

The control X-ray examination was made in $1^{\text {st }}, 2^{\text {nd }}$ and $3^{\text {rd }}$ month after surgery. The animals were euthanized using intravenous phenobarbital injection. The post mortal probes of parietal bones with implants were taken in $1^{\text {st }}, 2^{\text {nd }}$ and $3^{\text {rd }}$ month after surgery.

2.4.1. Histological evaluation. The histological samples, after decalcification process (Osteosoft ${ }^{\circledR}$ ) were dehydrated in 

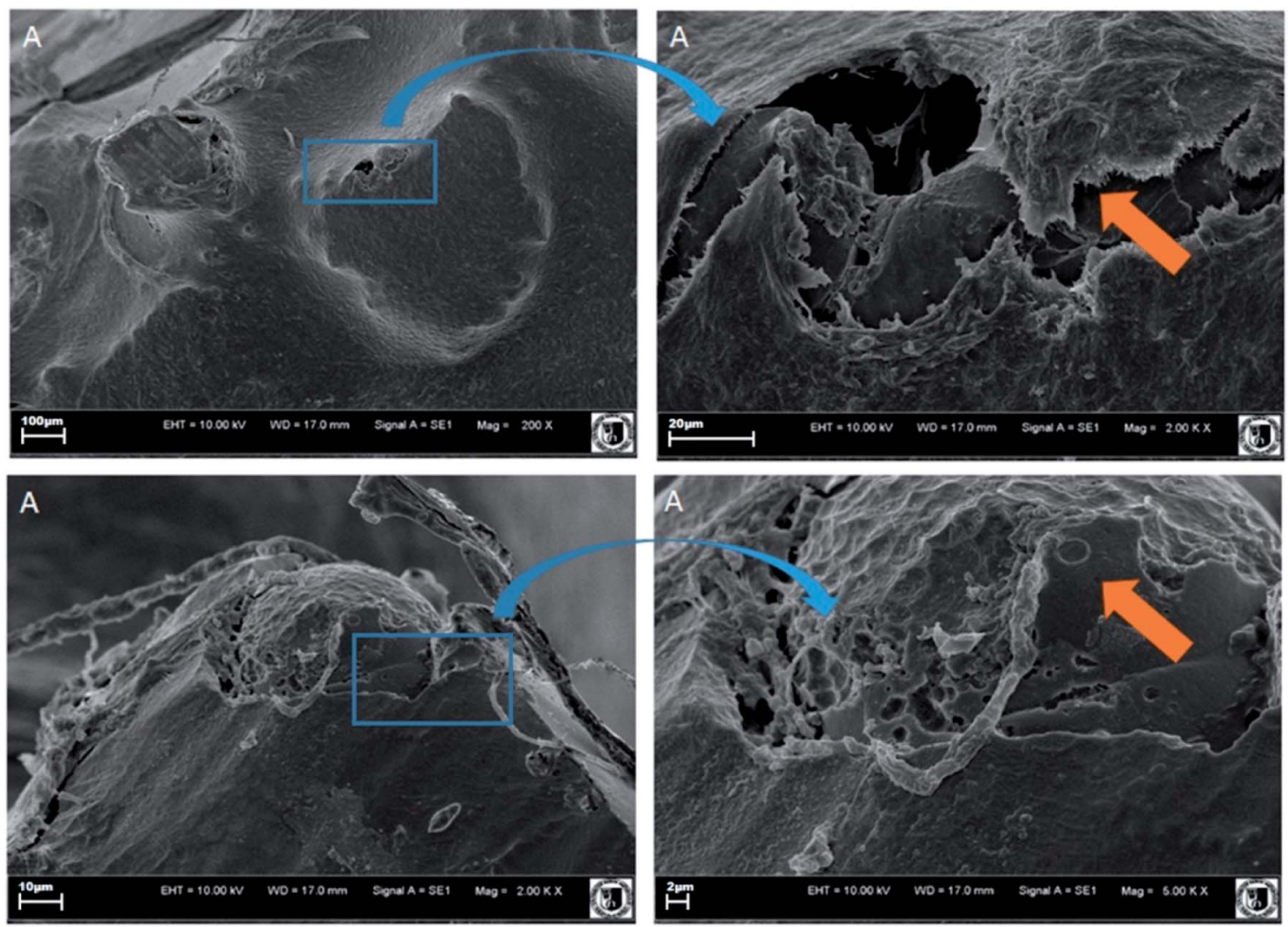

Fig. 11 SEM pictures of implants overgrown with new formed bone: A - control group

alcohol series and embedded in paraffin. Sections $5 \mu \mathrm{m}$ thick were stained with haematoxylin and eosin and Masson-Goldner trichrome (Masson-Goldner staining kit, Merck). Material was analysed in light microscope (80i Eclipse, Nikon).

Microscopic analysis of samples A and B were evaluated using EVO LS15 ZEISS Scanning Electron Microscopy (Zeiss, Jena, Germany). The tested samples were dehydrated in a series of ethanol solutions, dried and sputtered with gold. ${ }^{27}$

\section{Results}

\subsection{Ti6Al7Nb implant characterization}

The cylindrical samples with the diameter $6.2 \mathrm{~mm}$ and a height of $2.5 \mathrm{~mm}$ were manufactured in accordance with 3D CAD data model (Fig. 1a). The Ti6Al7Nb implants manufactured by SLM are shown in Fig. 1c.

To verify the obtained data, analysis of implant was additionally performed using different kinds of physicochemical approaches. Micrographs of the implant structure before (A) and after (B) surface modifications were visualized using the Scanning Electron Microscope EVO MA25 (Zeiss) in Fig. 2.

The chemical modification process (see Fig. 2c and d) has improved the quality of the implants surface. The chemical reagent used resulted in gradual smoothing of the strut surfaces, reducing the number of the powder particles loosely connected to each of the analyzed area and enabled the removal of loose powder particles left after manufacturing process.
Additionally technical computed tomography (Zeiss METROTOM 1500) was used to record the external and internal geometry ${ }^{3,14}$ of the fabricated structures based on the performed reconstruction. Total porosity of the reconstructed structures was at level of $50-60 \%$. Results of the surface area on whole volume of the implants was at the level of $315 \mathrm{~mm}^{2}$ and 260 $\mathrm{mm}^{2}$, respectively for the control (A) and test sample (B), which confirms the beneficial effect of the use of a chemical bath for smoothing the struts surfaces.

Moreover, the formation of the Ti6Al7Nb nanopowder and the obtained Ti6Al7Nb implants were observed by the XRD measurement (see Fig. 3). As can be seen, pure hexagonal phases corresponding to the reference standard of the titanium (ICSD - 426981) are observed for all samples. ${ }^{28}$

The quality of structural Rietveld refinement was checked by $R$-values to detect the consistency with a hexagonal structure. However, a difference in the observed and calculated patterns is the best method to evaluate the Rietveld refinement. Moreover, other parameters with additional functions were applied to find a structural refinement with better quality and reliability. As can be seen, Fig. 4 shows a good agreement between the observed XRD pattern and the theoretical fit calculation for different form of $\mathrm{Ti}^{0}$ which implicate the success of the Rietveld refinement method as displayed by the small differences of the ( $Y_{\mathrm{Obs}}$ $\left.-Y_{\text {Calc }}\right)$ intensity. The base lines during this method were used. The projection of the unit cell with the indication of the 

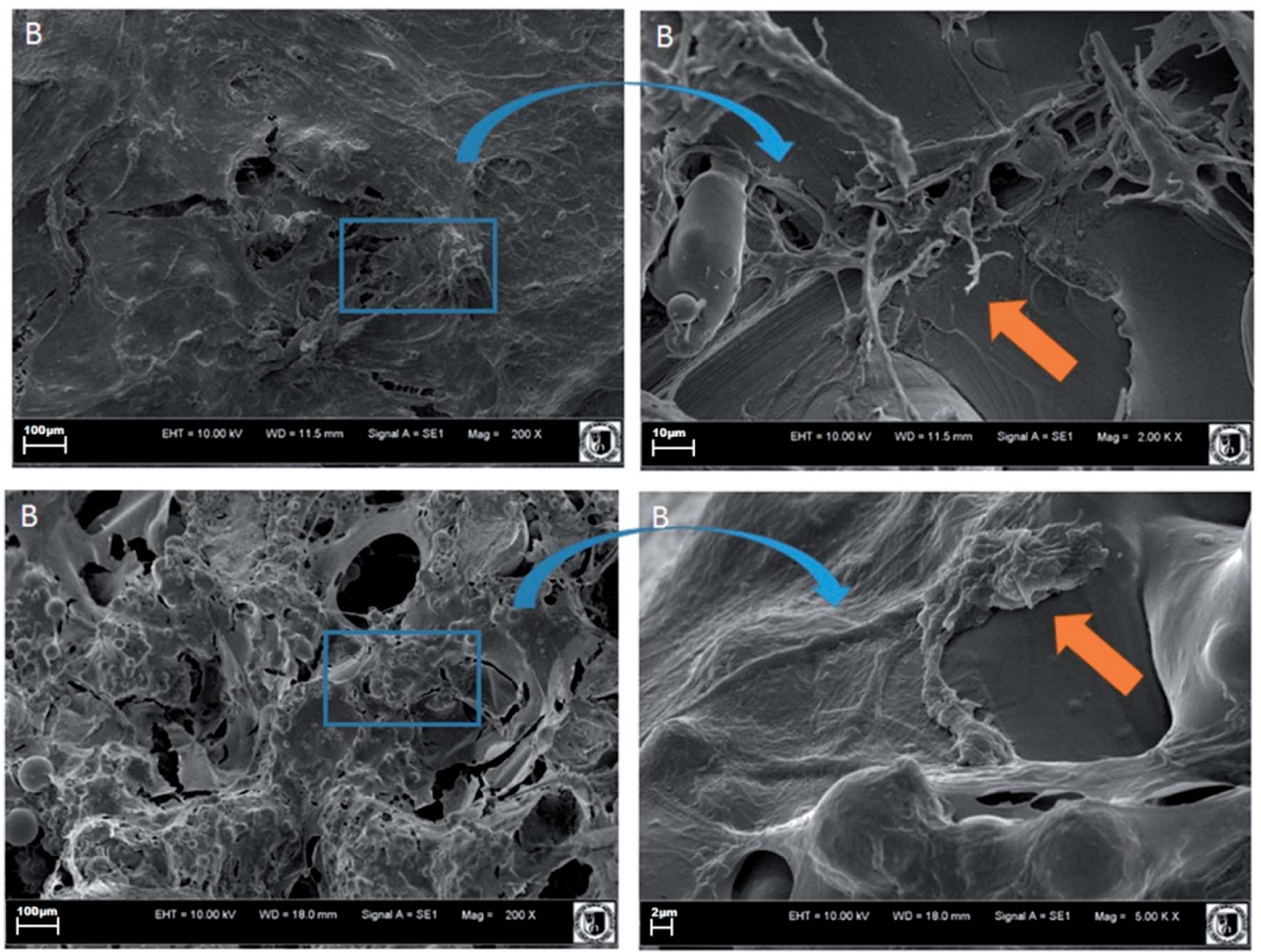

Fig. 12 SEM pictures of implants overgrown with new formed bone: B - test group.

coordination polyhedra are presented in Fig. 5 whereas results of calculations are given in Table 2 .

The general trend has been observed that all unit cell parameters increase with an increase in the annealing temperature or otherwise, with an increase in the particle size.

In order to estimate the particle size of the Ti6Al7 $\mathrm{Nb}$ nanoparticles the TEM images were measured (see Fig. 6a and b). The particle size was around $30 \mathrm{~nm}$ with narrow size distribution $\pm 5 \mathrm{~nm}$. Particles were not agglomerate and adopted regular shapes. The SAED images showed the appearance of welldeveloped and spotty rings with positions and distances close to the reference standards (see Fig. 6c).

\subsection{Clinical observation and $\mathrm{X}$-ray examination}

The wounds after surgical procedures healed without complication. The sutures were removed 10 days after surgery. During the experiment, the clinical status of animals was good, the food and water intake were normal. The implant localization was identificated in X-ray examination (see Fig. 7). A narrow shadow area around the implant was visible in every stage of the experiment. It is result of different calcium saturation in tissues. There were observed no differences between control and test groups by the X-ray analysis. Moreover, there was not observed any differences on the X-ray picture of skull implanted area after 1, 2 and 3 month healing. The bone tissue reactions surrounding implants were not stated.

\subsection{Macroscopic observations}

After $1^{\text {st }}$ and $2^{\text {nd }}$ month, grafts were covered by thin and transparent tissue in both implants A and B. The implants were strongly attached to the surroundings tissues. After 3 months, the implants were covered by a thick white tissue, both in the initial state (A) and modified (B). The surrounding bone tissue looked macroscopically normal.

\subsection{Histology}

After 1 month, the space between implant A and surrounding bone was filled by fibrous or loose connective tissue and small particles of implanted material were visible (see Fig. 8A1-A3). In contrast, around the modified implant (B) inside connective tissue, the areas of forming spongy bone tissue (see Fig. 8B1 and B2) were visible. The neutrophiles, eosinophiles and macrophages were present in the connective tissue in the immediate vicinity of the implant. A large number of collagen fibers were observed from the spongy bone side.

After 2 months, connective tissue with ossification centres and spongy bone were observed around group A implants. The large number of small particles of the implanted material was preserved. In a connective tissue the irregular net of collagen fibers were observed (see Fig. 9A1 and A2). In group B, the connective tissue and spongy bone were observed. A few particles of implanted material were visible (see Fig. 9B1 and B2). 

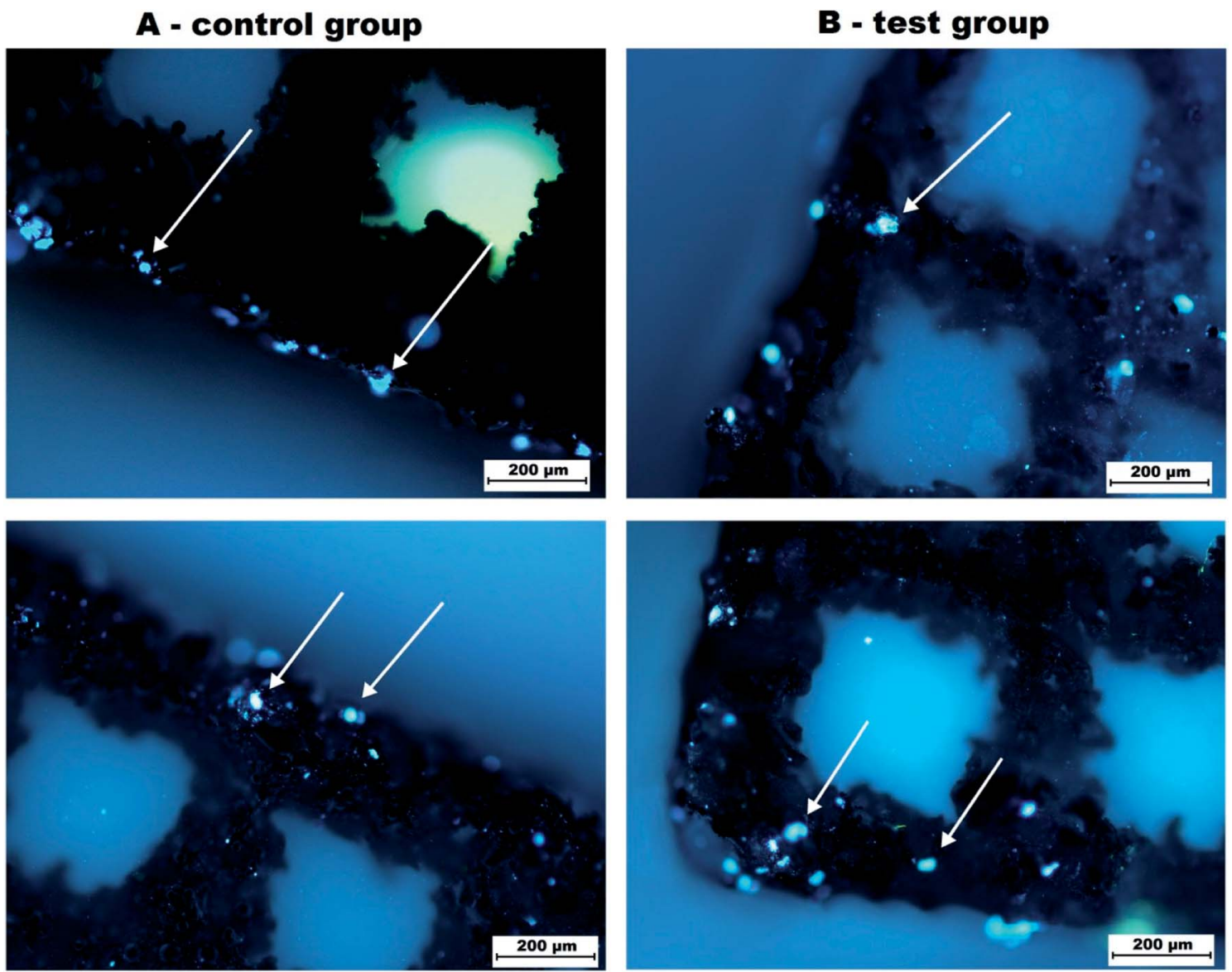

Fig. 13 Fluorescence. Pictures of implants overgrown with DAPI positive signal cells (marked with arrows).

After 3 months, implants A were surrounded by a double layer of connective tissue. The inner layer was loose and rich in morphotic elements and outer one was built with fibrous tissue with many new bone formation centres. In a tissue-infiltrated implant, the fibroblasts, fibrocytes, neutrophiles and eosinophiles were visible (see Fig. 10A1 and A2). Around implants B, the histological picture was similar, but eosinophiles were more numerous (see Fig. 10B1 and B2). Such changes are characteristic for mild inflammation process associated with reaction of the tissues to the implant.

\subsection{Scanning electron microscope (SEM)}

Performed SEM analysis revealed that Ti6Al7Nb implants, from group A has been overgrown with new formed bone (arrow) (see Fig. 11).

Higher magnification revealed that new formed bone as well as connective tissue has been well penetrated the surface of transplanted materials. However, still after 3 months of transplantation some of non-overgrowth surface was observed.

In the second group B, the cranial as well as new formed bone has been covered all tested surface of investigated implants (see Fig. 12).

The new formed bone and connective tissue well overgrowth the surface of fabricated materials.

\subsection{Fluorescence analysis of cell-implant interaction in vitro}

3.6.1. Analysis of cell adhesion. After incubation with cell culture in vitro the implant was removed with attached cells and analysed in fluorescence microscope. The analysis of cell adhesion to the implant revealed numerous positive signals located mainly at the edge of the implant. In test group, the total number of the cells was visibly higher than in control group. In the centre, the amount of cell was similar in both groups. In this analysis, the remnants of the dead cells with positive signal were eliminated from the analysis (see Fig. 13).

3.6.2. The changes in cell culture in contact with implant material. This analysis revealed the retarded cell growth in both experimental groups. The cells are arranged in less dense manner, however, contain elongated cells, interconnected with numerous processes (Fig. 14). In group A, large fragments of bioimplants are visible in material, which have been flushed out of the implant. That is a result of the technological processes used to produce it. Large number of small fragments remain poorly attached to the core of the implant. During contact with cells, these fragments are rinsed and get between the cells. They are not particularly toxic, but there are areas around them where there are no cells. In group B, after rinsing the bioimplant, a different characteristic feature is visible. The cells become less elongated, and the cytoskeleton slightly fills cells. 

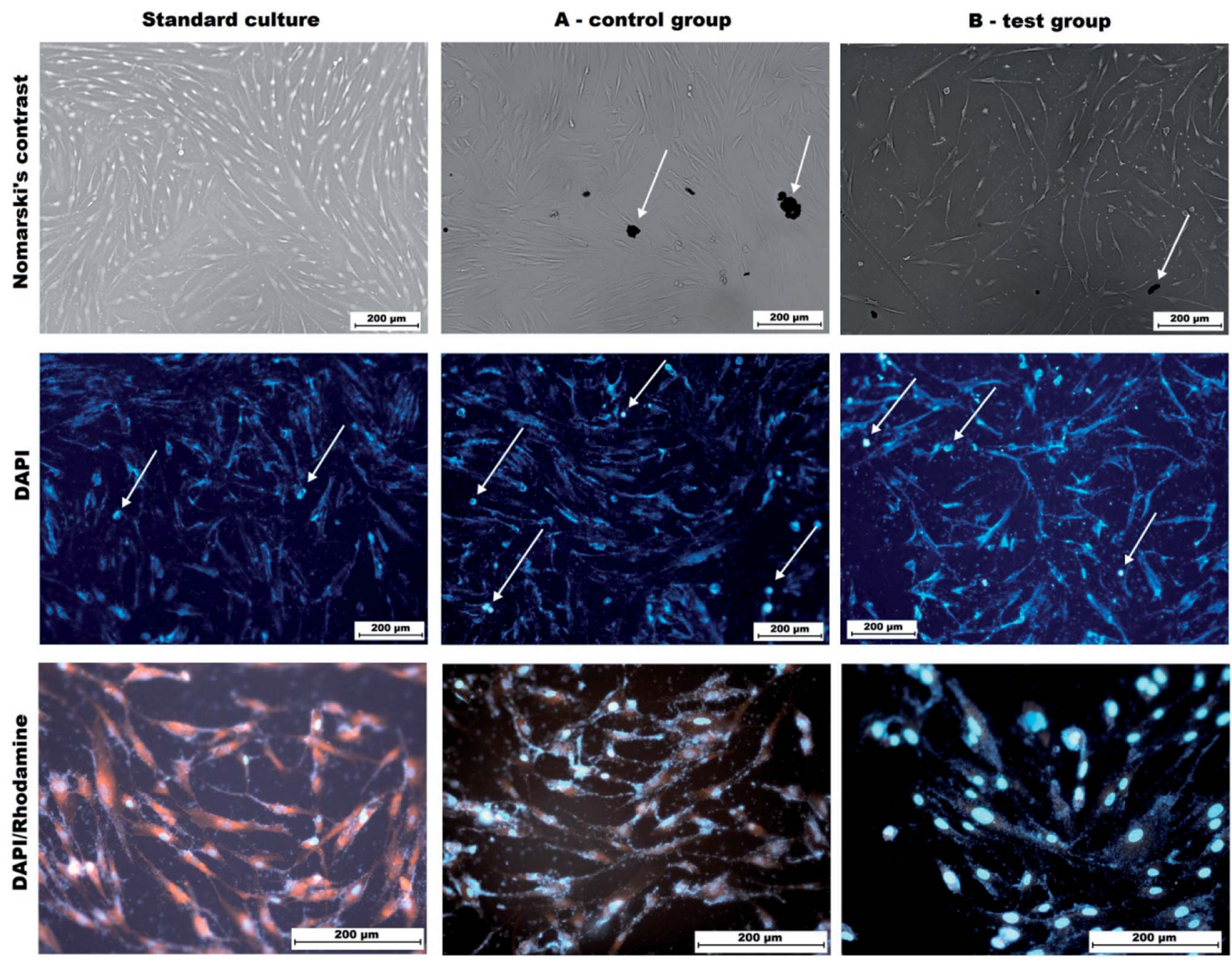

Fig. 14 Cytotoxic activity of implant material. Remnants of the bioimplant material is visible in both tested groups (black arrow). In DAPI attaining, visible cells undergoing the apoptosis (white arrow). DAPI/RP staining revealed that in tested group some changes in cytoskeleton can be observed Mag $100 \times, 200 \times$ and 400x.

Cytotoxicity analysis using DAPI alone showed the highest mortality of cells in group A. Despite rinsing, in group B also small molecules from the implant can be observed (Fig. 14).

\section{Discussion}

The SLM technology as an additive manufacturing process provides possibility of manufacturing homogenous functional structures (implants) having certain chemical, biological and mechanical properties suited to the expected actual load, deformation and displacement resulting from an individual's anatomy and physiology. Artificial bone implants can be used in tissue engineering that is an interdisciplinary field of science, focused on treating large cavities of bone. ${ }^{29}$ Designed and manufactured from Ti6Al7Nb porous structures are promising and suitable for replacing bone tissue damage, due porosity which effectively provides integration with the surrounding tissue and its high mechanical properties that are similar to those of bone structure. ${ }^{22}$ These new structures, as opposed to porous titanium and ceramic coating, have larger porosity and provide better friction with bone. These characteristics may enable increased bone ingress resulting in a stronger boneimplant connection which in turn may facilitate the development of improved treatments for musculoskeletal repair and reconstruction..$^{30,31}$

The current animal study shows that the discs (plain, coated with $\mathrm{HA}$ or $\mathrm{SiO}_{2}-\mathrm{TiO}_{2}$ ) made of Ti6Al7Nb manufactured with use of SLM technology are well biologically tolerated, without producing any adverse reactions. The samples used in this study were implanted into the cranial bone of New Zealand rabbits. Ti6Al7Nb implants and Ti6Al7Nb coated with HAp showed better results, which could suggest a possible enhancement of osteoconductive properties by hydroxyapatite infiltration. ${ }^{32}$

Current results indicate, that both materials (non-modified A and modified B) were successfully implanted without significant influence on the health status of experimental animals. Although, the X-ray image does not properly allow to evaluate implants osseointegration. Macroscopically all grafts were covered with thick white tissue and strongly stabilized by 

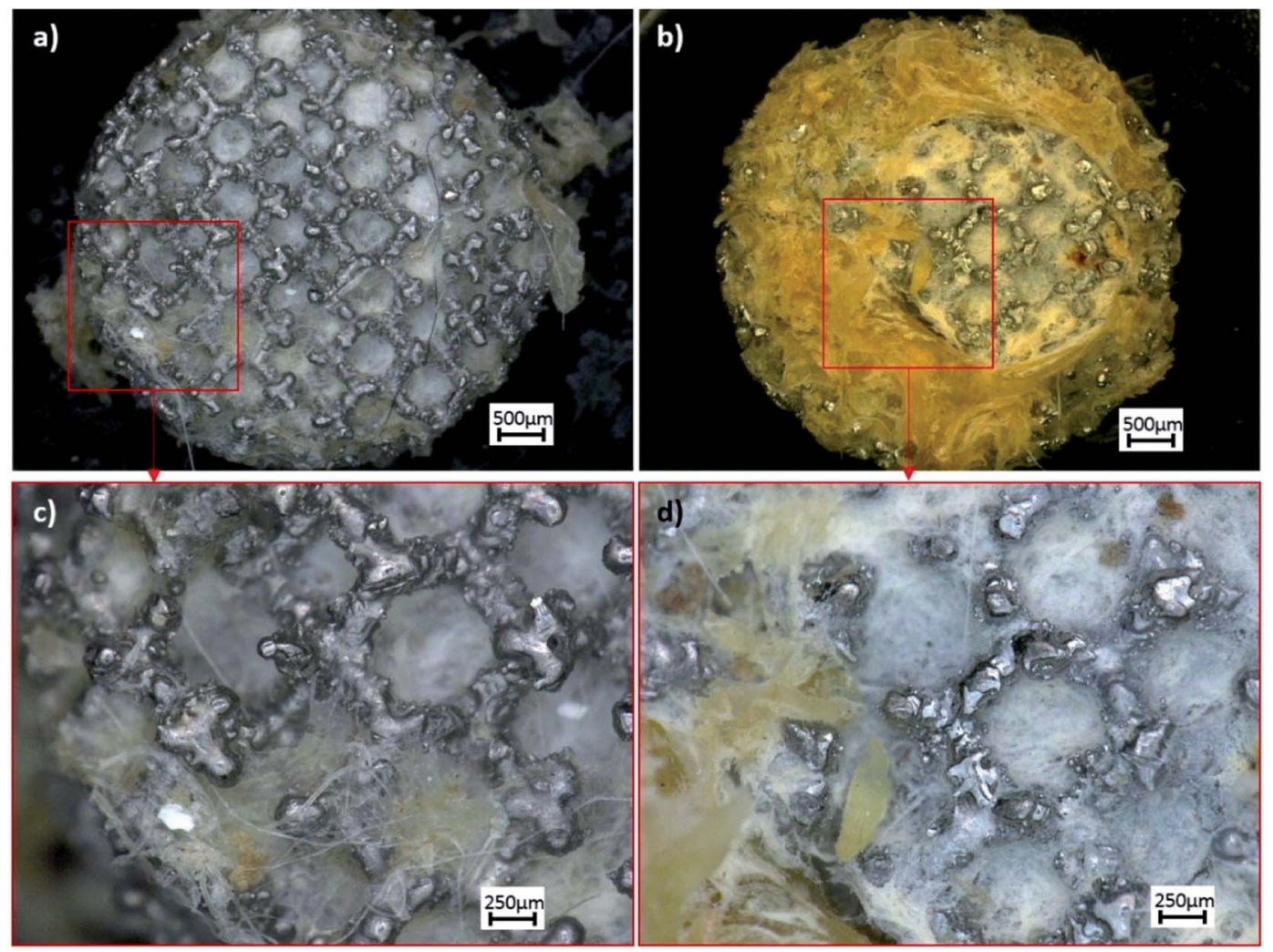

Fig. 15 Macroscopic pictures of implants overgrown with new formed bone: (a and c) A - SLM process (control group); (b and d) B - after chemical etching (so-called test group).

surrounding tissues in the $3^{\text {rd }}$ month after surgical intervention (see Fig. 15).

Histological investigations proved that B implants was causing better response of surrounding tissues during healing. The B implant connective tissue contained the ossification centers and spongy bone tissue after one month. It means earlier than in cause of A implants. After two months only few particles of implanted material was still visible in the former location of B grafts. The neutrophiles, eosinophiles and macrophages were visible in the connective tissue in both causes. The collagen fibres of connective tissue surrounding A implants were more irregular. After three months both implants were surrounded with double layer of connective tissue. SEM analysis indicated that only modified implant (B) were fully penetrated with new formed bone tissue after $3^{\text {rd }}$ month. The smoothest surface microstructure proved the carrageen gels. The above-mentioned results proved the hypothesis of better tolerance, healing process and tissue implantation of modified B implants.

Finally, the ability of $S$. aureus adherence and biofilm formation on Ti6Al7Nb implants produced by SLM were proved. $^{3}$ Taking under consideration that more than half of prosthesis infections are caused by $S$. epidermidis and $S$. aureus ${ }^{33}$ the chemical bathing technique reducing the adhesion potential would be enough to prevent biofilm formation in $v_{i t r o}{ }^{26}$ and in vivo, using the animal models.

Post-SLM surface modifications, chemical etching, influence the microorganisms biofilm formation abilities on implant surfaces. The B implants were better tolerated in animal models, causing more appropriate and desirable healing process and seems to be more favorable implant modification than ultrasonification.

\section{Conclusions}

In this study, the nanostructured Ti6Al7Nb alloy was processed by Selective Laser Melting method and the nanostructure and biological in vivo properties were investigated. A detailed structural study using X-ray diffraction and Rietveld analysis confirmed the nanocrystalline nature of the samples. The primary size of the particles was estimated to be in the range of $25-90 \mathrm{~nm}$ with a fairly narrow size distribution.

The experiment proved that implanted material was well tolerated in living organism, the inflammatory cells infiltration was limited in both cases. The bone tissue reconstruction process was visible. The Ti6Al7Nb implants after chemical etching showed lesser number of released particles in surrounding tissues. The results proved the accessibility of the Ti6Al7Nb implants for medical use. Further investigations will consist in experimental fracture healing using implant printed with 3D technique.

Based on this research, it was found that the implants made from nanostructured Ti6Al7Nb alloy do not show chronic systemic toxicity. Tests conducted in vivo using rabbits show the proper biological reaction of living organism on the presented implants. 


\section{Conflicts of interest}

The authors declare that there is no conflict of interests regarding the publication of this paper.

\section{Acknowledgements}

This work was supported by a grant STM.B040.16.006 from Wroclaw Medical University and statutory grant 0401/0022/17 from Wrocław University of Science and Technology. Moreover, Financial support from the National Science Centre over the course of the realization of the projects 'Preparation and characterization of nanoapatites doped with rare earth ions and their biocomposites' (no. UMO-2012/05/E/ST5/03904) and 'Preparation and characterisation of biocomposites based on nanoapatites for theranostic' (no. UMO-2015/19/B/ST5/01330) are gratefully acknowledged. Furthermore, this project is supported by Wroclaw Centre of Biotechnology and The Leading National Research Centre (KNOW) programme, for years 20142018.

\section{References}

1 K. Marycz, P. Sobierajska, A. Smieszek, M. Maredziak, K. Wiglusz and R. J. Wiglusz, $\mathrm{Li}^{+}$activated nanohydroxyapatite doped with $\mathrm{Eu}^{3+}$ ions enhances proliferative activity and viability of human stem progenitor cells of adipose tissue and olfactory ensheathing cells. Further perspective of nHAP: $\mathrm{Li}^{+}, \mathrm{Eu}^{3+}$ application in theranostics, Mater. Sci. Eng., C, 2017, 78, 151-162.

2 K. Marycz, R. Pazik, K. Zawisza, K. Wiglusz, M. Maredziak, P. Sobierajska and R. J. Wiglusz, Multifunctional nanocrystalline calcium phosphates loaded with Tetracycline antibiotic combined with human adipose derived mesenchymal stromal stem cells (hASCs), Mater. Sci. Eng., C, 2016, 69, 17-26.

3 P. Szymczyk, A. Junka, G. Ziolkowski, M. Bartoszewicz, D. Smutnicka and E. Chlebus, The ability of S.aureus to form biofilm on the Ti-6Al-7Nb bone scaffolds produced by Selective Laser Melting and subjected to the different types of surface modifications, Acta Bioeng. Biomech., 2013, 15, 69-76.

4 D. R. Murdoch, S. A. Roberts and V. G. Flower, Infection of orthopedic prostheses after Staphylococcus aureus batceremi, Clin. Infect. Dis., 2001, 32, 647-649.

5 J. K. Ellington, M. Harris, M. C. Hudson, S. Vshin, L. X. Webb and R. Sherertz, Intracellular Staphylococcus aureus and antibiotics resistance: implication for treatment of staphylococcal osteomyelitis, J. Orthop. Res., 2006, 24, 87-93.

6 H.-C. Flemming, J. Wingender, U. Szewzyk, P. Steinberg, S. A. Rice and S. Kjelleberg, Biofilms: An Emergent Form of Bacterial Life, Nat. Rev. Microbiol., 2016, 14, 563-575.

7 D. Campoccia, F. Testoni, S. Ravaioli, I. Cangini, A. Maso, P. Speziale, L. Montanaro, L. Visai and C. R. Arciola, Orthopedic implant-infections. Incompetence of Staphylococcus epidermidis, Staphylococcus lugdunensis and Enterococcus faecalis to invade osteoblasts, J. Biomed. Mater. Res., Part A, 2016, 104, 788-801.

8 M. F. Lopez, A. Gutierrez and J. A. Jimenez, In vitro corrosion behaviour of titanium alloys without vanadium, Electrochim. Acta, 2002, 47, 1359-1364.

9 X. Liu, P.-K. Chu and C. Ding, Surface modification of titanium, titanium alloys, and related materials for biomedical application, Mater. Sci. Eng. R Rep., 2004, 47, 49-121.

10 K. Marycz, A. Smieszek, J. Grzesiak, A. Donesz-Sikorska and J. Krzak-Ros, Application of bone marrow and adiposederived mesenchymal stem cells for testing the biocompatibility of metal-based biomaterials functionalized with ascorbic acid, Biomed. Mater., 2013, 8, 065004 .

11 A. Smieszek, A. Donesz-Sikorska, J. Grzesiak, J. Krzak and K. Marycz, Biological effects of sol-gel derived $\mathrm{ZrO}_{2}$ and $\mathrm{SiO}_{2} / \mathrm{ZrO}_{2}$ coatings on stainless steel surface-In vitro model using mesenchymal stem cells, J. Biomater. Appl., 2014, 29, 699-714.

12 B. R. Levine, S. Sporera, R. A. Poggie, C. J. Della Vallea and J. J. Jacobs, Experimental and clinical performance of porous tantalum in orthopedic surgery, Biomaterials, 2006, 27, 4671-4681.

13 C. J. Della Valle, N. W. Mesko, L. Quigley, A. G. Rosenberg, J. J. Jacobs and J. O. Galante, Primary total hip arthroplasty with a porous-coated acetabular component, J. Bone Jt. Surg., Am. Vol., 2009, 91, 1130-1135.

14 S. Van Baela, G. Kerckhofs, M. Moesen, G. Pyka, J. Schrooten and J. P. Kruth, Micro-CT-based improvement of geometrical and mechanical controllability of selective laser melted Ti6Al4V porous structures, Mater. Sci. Eng., A, 2011, 528, 7423-7431.

15 I. Michalak, K. Chojnacka and K. Marycz, Using ICP-OES and SEM-EDX in biosorption studies, Mikrochim. Acta, 2011, 172, 65-74.

16 G. Giavaresi, M. Fini, A. Cigada, R. Chiesa, G. Rondelli, L. Rimondini, P. Torricelli, N. N. Aldini and R. Giardino, Mechanical and histomorphometric evaluations of titanium implants with different surface treatments inserted in sheep cortical bone, Biomaterials, 2003, 24, 1583-1594.

17 J. Liu, P. Wang, C.-C. Chub and T. Xi, A novel biodegradable and biologically functional arginine-based poly(ester urea urethane) coating for $\mathrm{Mg}-\mathrm{Zn}-\mathrm{Y}-\mathrm{Nd}$ alloy: enhancement in corrosion resistance and biocompatibility, J. Mater. Chem. $B, 2017, \mathbf{5}, \mathbf{1 7 8 7 - 1 8 0 2 .}$

18 W. H. Kao, Y. L. Su and Y. T. Hsieh, Effects of Duplex Nitriding and TiN Coating Treatment on Wear Resistance, Corrosion Resistance and Biocompatibility of Ti6Al4V Alloy, J. Mater. Eng. Perform., 2017, 26, 3686-3697.

19 Y. Stetsyshyn, J. Raczkowska, O. Lishchynskyi, K. Awsiuk, J. Zemla, P. Dabczynski, A. Kostruba, K. Harhay, H. Ohar, B. Orzechowska, Y. Panchenko, P. Vankevyche and A. Budkowski, Glass transition in temperature-responsive poly (butyl methacrylate) grafted polymer brushes. Impact 
of thickness and temperature on wetting and morphology, cell growth, J. Mater. Chem. B, 2018, 6, 1613-1621.

20 R. J. Wiglusz, B. Pozniak, K. Zawisza and R. Pazika, An upconverting HAP@ $\beta$-TCP nanocomposite activated with $\mathrm{Er}^{3+} / \mathrm{Yb}^{3+}$ ion pairs for bio-related applications, RSC Adv., 2015, 5, 27610-27622.

21 A. F. Junka, P. Szymczyk, A. Secewicz, A. Pawlak, D. Smutnicka, G. Ziolkowski, M. Bartoszewicz and E. Chlebus, The chemical digestion of Ti6Al7Nb scaffolds produced by Selective Laser Melting reduces significantly ability of Pseudomonas aeruginosa to form biofilm, Acta Bioeng. Biomech., 2016, 18, 115-120.

22 A. Pawlak, P. Szymczyk, G. Ziółkowski, B. Dybala and E. Chlebus, Fabrication of microscaffolds from Ti-6Al-7Nb alloy by SLM, Rapid Prototyping J., 2015, 21, 393-401.

23 L. Lutterotti, S. Matthies and H.-R. Wenk, MAUD: a Friendly Java Program for Material Analysis Using Diffraction, IUCr Newsl. CPD, 1999, vol. 21, pp. 14-15.

24 L. B. McCusker, R. B. Von Dreele, D. E. Cox, D. Louer and P. Scardi, Rietveld refinement guidelines, J. Appl. Crystallogr., 1999, 32, 36-50.

25 K. Lejaeghere, V. Van Speybroeck, G. Van Oost and S. Cottenier, Error estimates for solid-state densityfunctional theory predictions: an overview by means of the ground-state elemental crystals, Crit. Rev. Solid State Mater. Sci., 2014, 39, 1-24.
26 J. Saczko, M. Dominiak, J. Kulbacka, A. Chwilowska and H. Kawczykowska, A simple and established method of tissue culture of human gingival fibroblasts for gingival augmentation, Folia Histochem. Cytobiol., 2008, 46, 117-119.

27 K. Kalinski, K. Marycz, J. Czogala, E. Serwa and W. Janeczek, J. Electron Microsc., 2012, 61, 47-55.

28 M. Bulanova, I. Fartushna, K. Meleshevich and A. Samelyuk, Isothermal section at $850^{\circ} \mathrm{C}$ of the $\mathrm{Ti}-\mathrm{Dy}-\mathrm{Al}$ system in the $\mathrm{Ti}-$ TiAl-DyAl2-Dy region, J. Alloys Compd., 2014, 598, 61-67.

29 K. Alvarez and H. Nakajima, Metallic Scaffolds for Bone Regeneration, Materials, 2009, 2, 790-832.

30 Y. Zhang, P. B. Ahn, D. C. Fitzpatrick, A. D. Heiner, R. A. Poggie and T. D. Brown, Interfacial frictional behavior: cancellous bone, cortical bone, and a novel porous tantalum biomaterial, J. Musculoskelet. Res., 1999, 3, 245-251.

31 A. D. Heiner and T. D. Brown, Frictional coefficients of a new bone ingrowth structure, Trans. Annu. Meet. - Orthop. Res. Soc., 2007, 32, 1623.

32 H. Rotaru, G. Armencea, D. Spirchez, C. Berce, T. Marcu, D. Leordean, K. Seong-Gon, L. Sang-Woon, C. Dinu, G. Baciu and $M$. Baciuţ, In vivo behavior of surface modified $\mathrm{Ti}$ alloys used in selective laser melting for custom-made implants. A preliminary study, Rom. J. Morphol. Embryol., 2013, 54, 791-795.

$33 \mathrm{~W}$. Zimmerli and P. E. Ochsner, Management of infection associated with prosthetic joints, Infection, 2003, 31, 99-108. 